\title{
Mobile phones: social impacts during the use phase
}

\author{
Poster extended abstract
}

\author{
Elisabeth Ekener and Elena Mokeeva \\ Division of Environmental Strategies Research \\ Centre for Sustainable Communications \\ KTH Royal Institute of Technology \\ Stockholm, Sweden \\ elisabeth.ekener@abe.kth.se, mokeeva@kth.se
}

Key words-Social life cycle assessment, use phase modeling, ICT, mobile phones, grounded theory, the day reconstruction method.

\section{PURPOSE}

Social Life Cycle Assessment (S-LCA) is a technique for assessing social impacts throughout the life cycle of a product, aiming to predict and improve social conditions of affected stakeholders. LCA requires a comprehensive approach, i.e. covering all phases of a product life cycle, however an approach for addressing the use phase in S-LCA is still under development and has been excluded in the majority of S-LCA studies. The primary objective of this study is to develop a methodological approach for assessing social impacts in the use phase, which would complement the existing S-LCA method. ICT is in the focus of this study, and particularly mobile phones, as our secondary objective is to contribute to the knowledge on sustainability impacts of ICT and the enabling potential of ICT.

\section{METHODS}

Recent research in S-LCA highlights the need for building the use phase assessment on a robust modeling of the use phase and including consumer behavior perspective. Our approach includes two methods for data collection and analysis: 1. semistructured interviews and a grounded theory approach [1, 2]; 2. the day reconstruction method (a diary method) [3]. The two methods will be applied separately; however, their results for the case study will be merged. The results obtained by two different methods will be compared, as well as applicability and feasibility of the methods and the approach in general will be discussed after the study is completed. The development of the methodology for assessing the use phase will go in parallel with the case study on mobile phones. Based on the data collected and with an aid of social practice theory, usage scenarios will be formed and related to them impacts recognized which will then be categorized according to a capabilities approach [4]. Moreover, impacts on a societal level and on future generations will be projected and discussed.

\section{RESULTS}

The main outcome of this study is a developed methodological approach for the use phase assessment in S-LCA, tested on a case of a mobile phone and potentially applicable on a generic level. Moreover, conclusions of the case study are anticipated to bring insights into impacts of ICT (a mobile phone in particular) on users and society. Positive impacts are important to be highlighted in order to support ICT as enabler of sustainable development and negative impacts (especially health issues) need to be lifted and shown in what conditions they tend to occur. Therefore, this study may become a starting point for further investigation of why certain impactful behaviors occur and how these could be changed in order to enhance the positive impacts and avoid negative impacts on all affected stakeholders.

\section{REFERENCES}

[1] B. G. Glaser and A. L. Strauss. The Discovery Of Grounded Theory. Chicago: Aldine Pub. Co., 1967. Print.

[2] K. Charmaz. Constructing Grounded Theory. London: Sage Publications, 2006. Print.

[3] D. Kahneman, A. B. Krueger, D. A. Schkade, N. Schwarz, A. A. Stone. A Survey Method For Characterizing Daily Life Experience: The Day Reconstruction Method. Science 306.5702 (2004): 1776-1780. Web.

[4] C. Reitinger, M. Dumke, M. Barosevcic, R. Hillerbrand. A Conceptual Framework For Impact Assessment Within SLCA. Int J Life Cycle Assess 16.4 (2011): 380-388. Web. 